AN ADDRESS AT A MEETING OF THE NATIONAL ASSOCIATION FOR CLEAN AIR THE DEVELOPMENT OF "MINIMUM-SMOKE" STOVES, THEIR APPLICATION AND EFFICIENCY AND PRESENT MARKET AVAILABILITY

by

C.E. BRAZIER

MANAGER : HEAT SERVICE DIVISION, TRANSVAAL COAL OWNERS ASSOCIATION

The Necessity

For many years the sight of smoke meant industrial development, progress and power. In more recent years however people have become increasingly aware of the dangers of air pollution. A few years ago the air over London became so saturated with smog and particles that many people died as a result of air pollution.

In Japan today for example, traffic officers work short shifts of one hour on duty and two hours off duty. During their off duties they have to breath oxygen to recover before going on duty again. This proves what a serious health hazard air pollution can become.

This has been a serious problem in overseas countries for a long time, and, although those countries have done much to improve matters, they face a tremendous uphill struggle because they waited until the problem had reached serious proportions before doing anything about it. Our problem is reaching serious proportions in some areas, but we still have time to adopt the attitude that prevention is better then cure - and, by the way, cheaper.

Whilst the awareness of the air pollution problem is relatively new to the average man in the street in South Africa, we in TCOA, together with the relevant authorities, and stove manufacturers have 
been aware of the fact that we will face the same problems one day, and we have been working on the development of smokeless type stoves for may years.

\section{African Areas}

All areas have their problems, but since you are influential gentlemen in your communities I would like us to concern ourselves with the problems as they exist in the densely populated African Urban Areas, and since Soweto is the largest of these, may I use it as my example. You have all seen the thick blanket of smoke settled over Soweto on a winter morning. The problem here is aggravated by the following factors -

1) Geographical

A large part of this area lies in a hollow and the smoke, being heavier than the surrounding air, settles.

2) Climatical

The Highveld winter is relatively severe - resulting in a more than usual amount of fuel being used, and the air remains cold until about midday before being warmed by the sun and able to rise.

3) Economical

The salaries of the average African are such that he cannot afford to use anything but bituminous coal in effective quantities, other fuels prove too expensive. Even if he could afford to lay on electricity to his home, the cost of using it would be a drain on his income.

We feel sure that you will agree that a changeover to smokeless air is desirable and the sooner this can be achieved the better. How then is this going to come about? 
The Change to Clean Air

It would be ideal if some authority could pay to have the new type of stove installed immediately, but as you can imagine this is an unrealistic dream. The Municipality has stated categorically that they will not enforce any immediate changeover.

I wish to stress that in the long term the problem will solve itself since it is envisaged that in the near future only the smokeless type appliances will be available, so that in, say ten years, all homes will have the smokeless type stoves installed. Our challenge then is to hasten this changeover.

In order to introduce the concept of smokeless stoves and to create an awareness of air pollution to the residents of Soweto the Johannesburg Municipality has set up three smokeless stove demonstration centres. We realise that these centres are not ideal in that not all questions asked by prospective clients can be answered by the staff on duty there, viz., the price of the stoves and the question of trade-ins on old stoves etc. There have already been letters to the press in this regard. Let me answer these questions now. Most of the stoves on display at these centres are already available through the normal retail furniture stores, and naturally the prices vary slightly from shop the shop. With regard to trade-ins, it is up to the shop concerned but since there is no ready market for the old type of stuve, and certainly the Johannesburg Municipality will not allow the old smoky type stove to be installed in future, we doubt whether many shops will be prepared to offer a worthwhile trade-in value.

It is for this reason that a R25 incentive has been offered by the Municipality to anyone who replaces his existing old type stove with a smokeless type. The R25 compensates the purchaser for lack of tradein facilities. The person purchasing a new type stove must present the invoice to the local superintendent's office in order to claim 
the refund.

It is not intended at this stage that stoves will be sold at the demonstration centres, but a scheme is being worked out at present whereby this may in future be done. It is a matter of getting all the manufacturers to agree on the details of the mechanics of this proposal.

\section{Our Duty to the Community}

Gentlemen, our community has a problem - a problem that is your challenge as leaders of that community to attempt to solve as quickly as possible and in the best interests of all concerned.

Problem No. 1 is a smoke-filled atmosphere - the solution is smokeless type stoves. Problem No. 2 is how to communicate with the people and encourage them to change. The solution rests with you and ourselves and we will do whatever we can but we must be guided by you, the senior members of your community. If we are going to communicate with others, let us start by communicating with each other. If any of you gentlemen have ideas which you think may be beneficial to the promotion of these appliances in the African areas, we would be pleased to hear from you to discuss these ideas. Your co-operation will be appreciated.

We now invite you to view all the appliances on display and please feel free to discuss any aspect of these with us before you leave.

March 14, 1973 